\title{
Automation of Psychological Selection Procedures for Personnel to Specific Activities
}

\author{
Ihor Prykhodko ${ }^{1}$, Stanislav Horielyshev $^{1 *}$, Yanina Matsehora ${ }^{1}$, Vasiliy Lefterov ${ }^{2}$, \\ Stanislav Larionov ${ }^{1}$, Olena Kravchenko ${ }^{1}$, Maksim Baida ${ }^{1}$, Olena Halkina ${ }^{3}$ and \\ Olena Servachak ${ }^{4}$ \\ ${ }^{1}$ National Academy of the National Guard of Ukraine, Kharkiv, 61001, Ukraine \\ ${ }^{2}$ National University “Odessa Law Academy”, Odessa, 65009, Ukraine \\ ${ }^{3}$ Kharkiv National University of Internal Affairs, Kharkiv, 61057, Ukraine \\ ${ }^{4}$ Donetsk National Technical University, Pokrovsk, 85300, Ukraine
}

\begin{abstract}
The article presents a universal method for determining the professional suitability (PS) of a candidate and an algorithm for forming a psychological profile for a specific profession based on determining the psychological potential of personality. The developed method is based on the use of automated support systems. Based on the obtained value of the integral indicator, a decision is made on the PS group of this candidate. This method adapts to the requirements of the profession to candidates, taking into account changes in the conditions of activity by adjusting the typical psychological profile of the personality. The developed method for determining a candidate's PS has been brought to practical implementation in the form of an Automated Psychodiagnostic Complex (APDC) "Psychodiagnostics." APDC has been tested on the example of the psychological selection procedures of personnel for military service in units with law enforcement functions. APDC allows to reduce the time and labor costs for conducting psychodiagnostic studies, increases the reliability of tests

ARTICLE INFO

Article history:

Received: 06 April 2021

Accepted: 19 November 2021

Published: 04 January2022

DOI: https://doi.org/10.47836/pjst.30.1.41

$\overline{\text { E-mail addresses: }}$

prikhodko1966@ukr.net (Ihor Prykhodko) port_6633@ukr.net (Stanislav Horielyshev) yanina_gora@ukr.net (Yanina Matsehora)

lefterov.vasil@gmail.com (Vasiliy Lefterov)

larionov1985@gmail.com (Stanislav Larionov)

elena_diamant@outlook.com (Olena Kravchenko)

maxbayda07@ukr.net (Maksim Baida)

yaen0110@gmail.com (Olena Halkina)

e.v.servachak@gmail.com (Olena Servachak) due to a higher degree of standardization of the testing procedure, increases the accuracy of assessing psychological characteristics, and reduces the likelihood of errors in the processing of test results. APDC can be used for recruiting in various sectors of the economy, education, and military sphere.

Keywords: Automation, extreme activity, integral indicator, personality characteristics, psychological selection procedures
\end{abstract}

* Corresponding author 


\section{INTRODUCTION}

Automation based on artificial intelligence and machine learning has increasingly been used to support managerial tasks and duties to enhance the quality and efficiency of information processing and decision-making (Langer et al., 2020). Solving the problem of determining professional suitability (PS) leads to the determination of a person's inclination to a particular category of professions, where his potential, psychophysiological reactions to external conditions, the ability to make adequate decisions depending on the circumstances are most fully revealed (Prykhodko, 2008). An employee who has developed professionally important psychological traits has better performance indicators (both qualitative and quantitative), is less prone to professional deformation, illness, and injury, his professional age is greater, and the cost of training is much lower (Vorobyova et al., 2012). It becomes the key to the high-quality fulfillment of the tasks set, raising the status of a person in a team and his self-esteem.

It is necessary to consider automation and decision support systems to get a clearer understanding of automated systems for personnel selection procedures (PSP). Sheridan and Parasuraman (2005) propose to consider automation as "a) the mechanization and integration of the sensing of environmental variables (by artificial sensors), b) data processing and decision making (by computers), c) mechanical action (by motors or devices that apply forces on the environment), d) and/or 'information action' by communication of processed information to people." We focus on the data processing and decision-making aspects of automation, followed by information action, where systems provide processed information to human decision-makers. This kind of automation is reflected by four broad classes of functions of automation: a gathering of information, filtering and analysis of information, decision recommendations, and action implementation (Parasuraman et al., 2000). With more of these functions realized within systems, the extent of automation increases. Systems that provide decision recommendations could be trained on previous data to fulfill classification (e.g., distinguishing suitable vs. non-suitable applicants) or prediction tasks (e.g., what applicants will most likely be high-performing employees). The outputs of those tasks can then be presented to human decision-makers. It is precisely the kind of automated system that the current paper refers to automated systems that gather and analyze the information as well as derive inferences and recommendations based on these steps. Such systems can aid hiring managers, psychologists in a large range of their duties (e.g., gathering and integrating of information, applicant screening), and their outputs can be used as an additional (or alternative) source of information for decision-makers (Langer et al., 2020).

Automated support systems for high-level cognitive tasks are an emerging topic in research and practice, especially within PSP. Within human resource management, current practical developments, and recent research point to a future where managers will 
collaborate with automated systems to work on tasks as varied as scheduling (Ötting \& Maier, 2018), PSP (Campion et al., 2016; Petrescu et al., 2015), including for military personnel (Farina et al., 2019) and law enforcement officers (Zhiltsova et al., 2005). Various automated support systems for PSP have been developed and implemented in the U.S. Armed Services and the Special Forces (Farina et al., 2019), Russian Federation (Zhiltsova et al., 2005), Ukraine (Zlepko et al., 2010), and other countries.

There are different approaches in the methodology of creating automated support systems for determining the PS of candidates. Skorupski et al. (2020) used a computergenerated fuzzy model based on linguistic variables to construct a candidate's PS profile. Anitei and Buzea (2012), Kabak et al. (2012), and Kelemenis and Askounis (2010) have proposed a fuzzy hybrid multicriteria decision-making approach that combines qualitative and quantitative factors. For this, the authors used a combination of Fuzzy ANP, Fuzzy TOPSIS, Fuzzy ELECTRE methods. Grechushkina (2020) developed indicators of the potential effect of introducing software and hardware psychodiagnostic complexes to determine the PS of future officers.

The emerging use of such systems, especially for PSP, might be due to the complexity of personnel selection. Automated decision support systems might help gather and combine information for large applicants, thus making selection procedures more efficient, and there is hope that they can attenuate adverse impact (Langer et al., 2020).

Thus, the problem of the automated support systems for PSP from auxiliary to the sphere of mandatory means of research is relevant since computer technology is increasingly penetrating the sphere of humanitarian disciplines, particularly psychology (Spielberger, 2004). Moreover, their use contributes to the rapid and most reliable determination of human PS to a specific category of professions.

The purpose of the study is to develop the method for determining the candidate's PS for a certain category of professions, taking into account his psychological potential and allowing him to predict success in a particular profession. Therefore, it is necessary to solve the following tasks to achieve the goal: (1) substantiate the methodology for the formation of a psychological profile with given parameters, depending on specialization; (2) to develop a method for calculating the integral indicator of PS based on the obtained test data and a given psychological profile; (3) offer tools for determining and automating the method of calculating candidate's PS for a certain category of professions.

\section{MATERIALS AND METHODS}

\section{Method of Formation Psychological Selection Procedures for Personnel to Specific Activities}

The method of formation PSP for personnel to specific activities is a system of consistently conducted activities developed by the authors and includes four main stages: studying the characteristics of professional activities and substantiating requirements; formation of a 
typical psychological profile; development of a method for calculating the integral indicator of the candidate's PS for a certain category of professions; deciding on PS.

The proposed method is based on the Eastern European classical approach for determining the PSP of specialists (Bodrov, 2007; Prykhodko, 2008), taking into account personality characteristics and features of future professional activity. This method is based on the principles used in the PSP in different countries. The choice of specific psychodiagnostic tests depends on the cultural characteristics of the subjects, the field of professional activity. The list of psychodiagnostic tests is formed based on the most common and recognized tests used for PSP in a particular country.

Several pilot studies were carried out during 2012-2014 to develop the psychodiagnostic tests battery used in this study. The objectives of these studies were to identify the relationship between the personality characteristics of candidates with the success of training in a higher military educational institution and the effectiveness of the professional activity. As a result of these studies, professionally important psychological characteristics and adequate psychological tests for their measurement were identified.

The flowchart of the method of formation PSP to specific activities is shown in Figure 1. Further, the stages of formation of the PSP to specific activities are discussed in more detail.

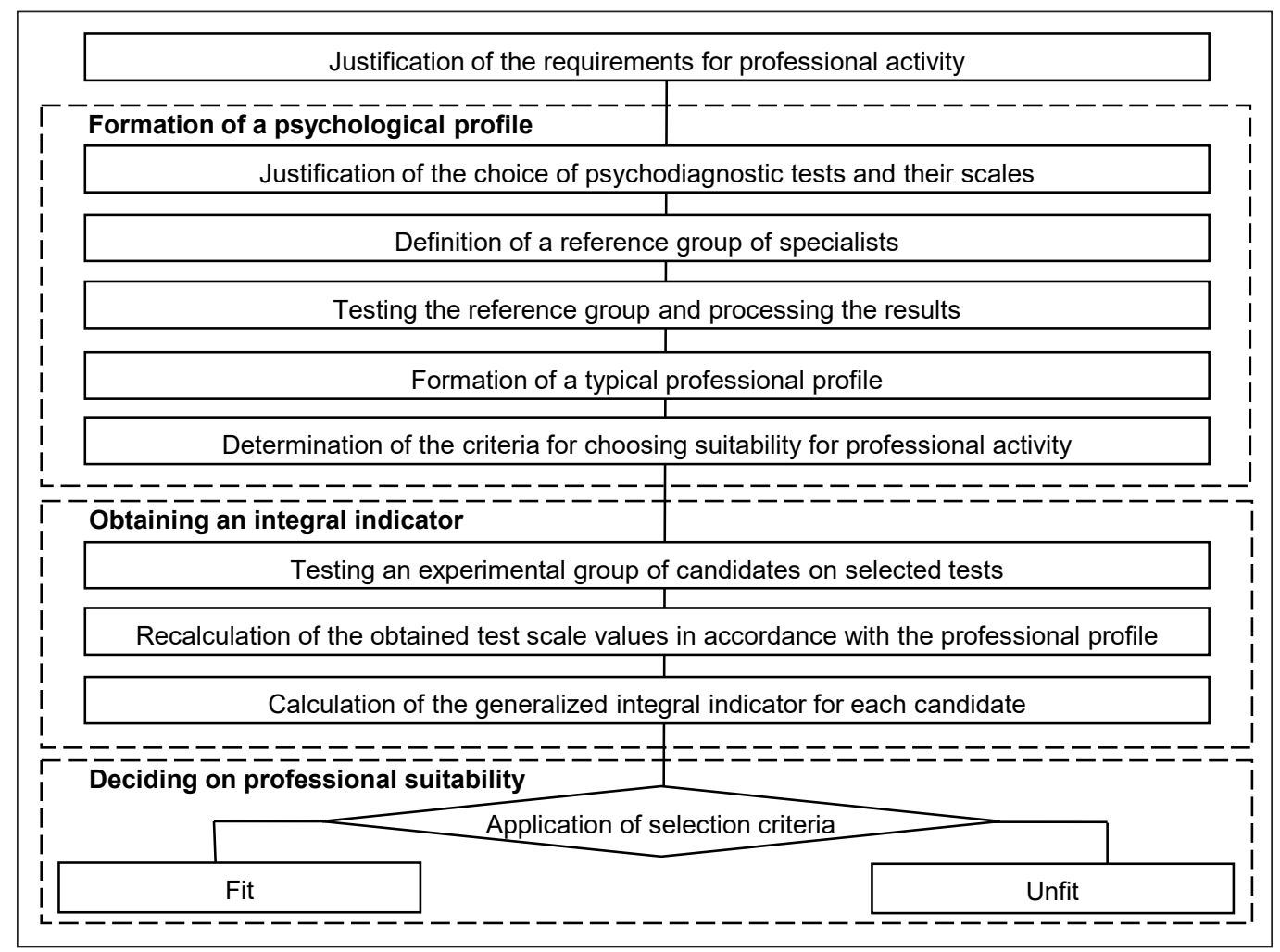

Figure 1. The flowchart of the method of formation psychological selection procedures for personnel to specific activities. 


\section{Method for Studying the Characteristics of Professional Activity and Justifying Requirements}

At this stage, the features of specific types of professional activity were studied, and the requirements for professionally important psychological characteristics of a personality were determined. The main method of psychological research of professional activity in various specialties is analytical professiography (Bodrov, 2007). Analytical professiography allows to study of the patterns, mechanisms, conditions, and factors of the productive development of personnel and the implementation of the chosen life strategy (Karpilovskaya et al., 1997; Melnyk et al., 2019).

As a result of such a study, the criteria for the success of professional activity are determined; the procedure for choosing psychological tests for assessing professionally important psychological characteristics necessary for the successful mastering of this profession is substantiated. For this, a professiogram (psychogram) is drawn up, which indicates professionally important psychological characteristics that allow the candidate to master a particular specialty successfully and quickly (Prykhodko, 2008). First, the revealed psychological characteristics were assessed on a five-point Likert scale in accordance with the following criteria: (1) the degree of importance of each quality for achieving the final goal (result), performing a specific task (element, operation); (2) the duration and frequency of application of this psychological characteristic to perform all types of activity (work process); 3) the duration and frequency of application of this psychological characteristic when performing a specific task (individual labor operations); (4) the degree of complexity of each psychological characteristic. Next, the average score of professionally important psychological characteristics was calculated. Thus, we obtained quantitative and qualitative indicators of professionally important psychological characteristics necessary for effective professional activity in a particular specialty. Further, these characteristics were assessed during psychodiagnostics of the candidate's PS.

\section{Formation of a Psychological Profile with Specified Characteristics Depending on the Category of Professions}

The formation of candidate's PS can be divided into the following stages: (1) definition of a test battery covering all aspects of this category of professions; (2) determination of reference groups of specialists, testing; (3) the formation of a typical psychological profile and the establishment of restrictions.

To determine the candidate's PS level for specific activities, proceed from psychological, psychophysiological, medical, and other criteria. It determines the choice of psychodiagnostic techniques that determine the degree of mastery of professional knowledge and skills (achievement tests) and the level of development of professionally important psychological characteristics. 
In accordance with the given characteristics of the profession, several experimental groups are formed: successful professionals, professionals, and low-performing employees. In each group, specialists in different age categories should be represented in approximately equal proportions.

In constructing the psychological profile, statistical data were used, on the one hand, obtained after testing the selected groups, and on the other hand, the ideal model (according to the given characteristics).

If psychological tests are used $n$, then a test vector is formed $\vec{T}=\left(T_{1}, T_{2}, \ldots, T_{n}\right)$. Each psychological test is characterized by its own set of scales $\vec{S}_{i}=\left(S_{i 1}, S_{i 2}, \ldots, S_{i k}\right)$. The number of scales $k$ in each test may differ. Then the psychological profile can be represented by a set of scales (individual psychological characteristics) in the form of a column vector $\vec{P}=\left(\begin{array}{c}\bar{S}_{1} \\ \bar{S}_{2} \\ \cdots \\ \bar{S}_{n}\end{array}\right)$, and the number of scales is calculated as in Equation 1:

$$
M=\sum_{i=1}^{n} k_{i},
$$

where $k_{i}$ - the number of scales in the i-th test.

In accordance with the key to the test $T_{i}$ used, a set of possible values is formed for each scale using Equation 2:

$$
S_{i j}=\left\{a_{1}, a_{2}, \ldots, a_{r}\right\}
$$

where $a_{1}$ - minimum scale value, $a_{r}$ - maximum scale value, $r$ - number of possible scale values, $i=1 \ldots n$ - psychological test number, $j=1 . . . k$ - scale number of the $\mathrm{i}$-th psychological test.

Based on the obtained statistical data of testing the experimental groups, for each scale of each test $S_{\ddot{y}}$, the distribution of a random variable of its values $\mathrm{P}^{a}$ is constructed and described by the distribution function $F(a)$ (Ventzel, 2006). Unfortunately, the scale values even in one test can differ by several orders of magnitude. Therefore, to take into account their contribution to the PS value, it is necessary to normalize the distribution $F(a)$ relative to the general ten-point universal scale $F_{10}(a)$ and approximate it in accordance with the given requirements for an ideal specialist in this profession.

Thus, for each psychological characteristic of each test, we obtain a distribution of the values of the survey results on a standard ten-point scale $F_{10 i j}(a)$. The totality of these distributions is the average psychological profile for this specialty. According to the comparison results, by correlation analysis of successful and poorly successful 
experimental groups, the most significant qualities in the psychological profile are identified and restrictions on the minimum value in $F_{10 i j}(a)$.

\section{The Method of Calculation the Integral Indicator of Professional Suitability Based on the Obtained Test Data and the Psychological Profiling}

The main task of the study was to develop a comprehensive indicator of the effectiveness of the professional activity, taking into account different aspects of the personality of the candidate. As a result, this made it possible to decide on its distribution into one of three suitability groups: unsuitable, conditionally suitable, and suitable.

The decision criterion used the principle of similarity of the candidate's profile to the average psychological profile of his representative. As an indicator used an integral indicator of PS, the basis of which was the assessment of characteristics on the scales of psychodiagnostic tests, the formation of the average value of the test using the created psychological profile, and the summation of these values over the entire set of tests.

At the first stage for each scale $S_{i}$, its values $a_{i j}$ were obtained in accordance with the key. Further, to take into account the contribution of all scales to the overall indicator of the psychodiagnostic test $T_{i}$, a generalized indicator for this test $P_{i}^{0}$ was formed by recalculating the values of the scales in accordance with the standard normalized distribution of a given profile $F_{10 i j}(a)$ and further averaging using Equation 3:

$$
P_{i}^{0}=\frac{\sum_{j=1}^{k_{i}} F_{10_{i j}}\left(a_{i j}\right)}{k_{i}}
$$

At the second stage after, obtaining the values of the generalized indicators for each test, derived the integral indicator $P S^{*}$ of the candidate's PS for a certain category profession by summing them up using Equation 4:

$$
P S^{*}=\sum_{i=1}^{n} P_{i}^{0} .
$$

Depending on the number of selected tests, covering professionally important psychological characteristics, the maximum possible value of the integral indicator of PS was calculated using Equation 5:

$$
P S_{\max }^{*}=10 * n
$$

where ${ }^{n}$-number of psychological tests. 
Empirical studies conducted with a control group of specialists in a specific profession (in this study, there were candidates for military service) made it possible to establish the selection criterion at the level $P S^{*}>0.6^{*} P S_{\max }^{*}$ (all candidates who scored more than $60 \%$ of the maximum possible value). As a result, the selected candidates had the necessary professional qualifications to fulfill their professional duties successfully.

Thus, using the developed method, an integral indicator of PS was obtained, which, in accordance with the selected criterion, made it possible to make an informed decision about the suitability of the candidate for this profession.

\section{Automation of the Method for Determining the Professional Suitability of a Candidate for a Certain Category of Professions}

When developing tools of the method for determining PS, the authors of the article paid special attention to the following aspects: automation of the individual and group testing procedures, automation of the processing of test results, their storage, and protection, as well as different ways of presenting individual and group testing results, depending on the tasks facing the psychologist (creation of an individual psychological support card, data transfer to the Word application, transfer of group testing data to the Excel application for further statistical processing) (Arestova et al., 1995; Matsehora et al., 2014; Vorobyova et al., 2012).

The implementation of this method was the creation of an Automated Psychodiagnostic Complex (APDC) "Psychodiagnostics." The specifics of the solution of the tasks are dictated by the need to build APDC both in the network version and in the local one. The functional diagram of the APDC "Psychodiagnostics" is shown in Figure 2.

In both construction options, two specialized operating modes of APDC are envisagedthe modes "Respondent" and "Psychologist." The "Respondent" mode allows you to conduct psychological testing of the subject according to a given set of psychological tests. The "Psychologist" mode gives the user full access to all the possibilities of the APDC, for example, the formation of psychodiagnostic tests battery for the given profession, setting the selection criteria and forming a standard psychological profile, obtaining an integral indicator, working with the database of the subjects and the results of their psychological testing.

When the system is deployed on a local computer, the equipment of these terminals coincides; that is, one personal computer (PC) is used. However, in the network implementation, several different PC are used: one is the "terminal" of the psychologist; the other is the terminal of the respondent. The exchange of information between the modules is carried out using a control and data exchange module, which control signals of the complex's operation, information flows pass.

In the "Respondent" mode, the following modules are used: the module of respondent identification, the module of test dialogue, and the module of automated psychodiagnostic 


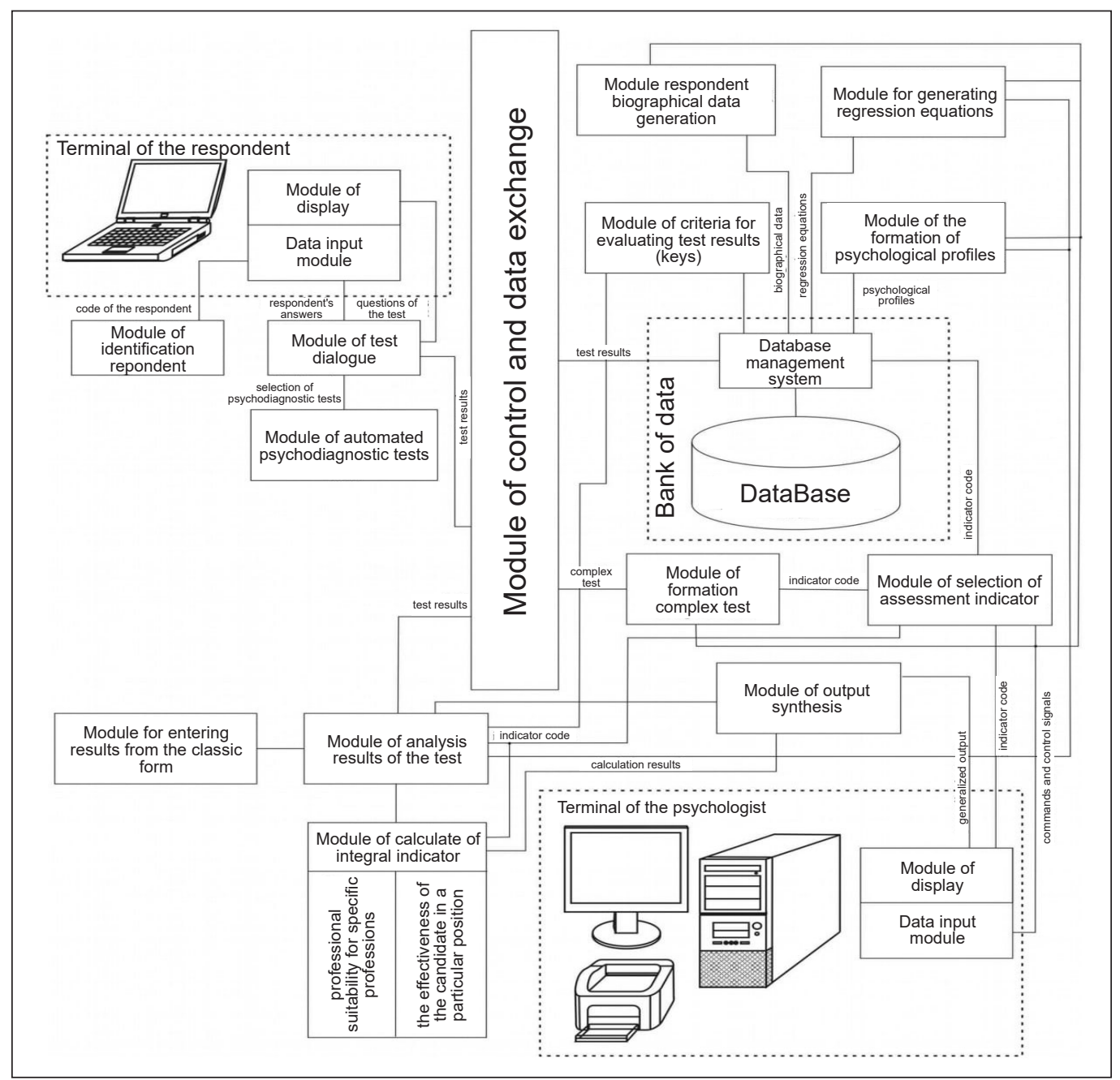

Figure 2. Functional diagram APDC "Psychodiagnosis"

tests. Finally, in the "Psychologist" mode, the functioning of the complex requires additional modules that significantly expand the psychologist's capabilities in the field of analysis of the results obtained and their display, calculation of various integral indicators (PS, including indicators for specific professions), values of regression equations the effectiveness of the candidate in a particular position, as well as testing.

Thus, the developed method for determining PS is brought to practical implementation based on a PC and tested in practice.

\section{RESULTS AND DISCUSSION}

Consider the use of the method on the example of the PSP of candidates for military service in units with law enforcement functions. 
All respondents $(\mathrm{N}=186)$ were divided into three groups in the experiment. Group 1 (n $=62$ ) was formed from the most experienced specialists from units with law enforcement functions (reference group), Group $2(\mathrm{n}=62)$ and Group $3(\mathrm{n}=62)$ were made up of respondents who were candidates for professional activities with law enforcement functions. The test results of Group 1 were used to form the typical psychological profile of the personality $F_{10 i j}(a)$. The determination of PS in Group 2 was carried out using the APDK "Psychodiagnostics," and in Group 3 without its use (testing was carried out on paper by the same methods, but with manual calculation, and the integral index of PS was not determined).

After a detailed study of the activities of the military personnel of such units and substantiation of professional requirements, a test battery was formed (Table 1) that covered almost all aspects of the personality (Matsehora et al., 2014; Vorobyova et al., 2012). The selection of these psychodiagnostic tests was based on PSP principles in postSoviet countries.

For the selected tests, using the results of Group 1, a typical psychological profile was formed, which consisted of 51 scales $\left(T_{1}-1\right.$ scale, $T_{2}-5$ scales, $T_{3}-8$ scales, $T_{4}-10$ scales, $T_{5}-9$ scales, $T_{6}-17$ scales, $T_{7}-1$ scale). For example, for the test $T_{1}$, one indicator, $S_{11}$, is evaluated - the intelligence coefficient. Its original range of points varies from 0 to 132. The distribution function $F(a)$ of intelligence points of the reference sample is shown

Table 1

Psychodiagnostic tests battery

\begin{tabular}{|c|c|c|c|}
\hline № & Test name & Test focus & $\begin{array}{c}\text { Test } \\
\text { designation }\end{array}$ \\
\hline 1 & "Progressive Matrices" (J. Raven) & $\begin{array}{l}\text { Common abilities that determine } \\
\text { the ability to master any activity }\end{array}$ & $T_{1}$ \\
\hline 2 & $\begin{array}{l}\text { "Temperament Structure Questionnaire of Self- } \\
\text { assessment" (B. Smirnov) }\end{array}$ & Features of temperament & $T_{2}$ \\
\hline 3 & $\begin{array}{l}\text { "The Motivation Questionnaire for Professional } \\
\text { Choice of Candidates for Service in the Ministry } \\
\text { of Internal Affairs of Ukraine" }\end{array}$ & Features of the choice motivation & $T_{3}$ \\
\hline 4 & $\begin{array}{l}\text { "Determining the Type of Accentuation } \\
\text { of Character Traits and Temperament } \\
\text { Questionnaire" (K. Leonhard, H. Schmieschek) }\end{array}$ & $\begin{array}{l}\text { Character traits and accentuations } \\
\text { that worsen adaptation to new } \\
\text { conditions }\end{array}$ & $T_{4}$ \\
\hline 5 & “Suicidal Risk Questionnaire” (A. Shmelev) & $\begin{array}{l}\text { Strong-willed features and suicidal } \\
\text { tendency }\end{array}$ & $T_{5}$ \\
\hline 6 & $\begin{array}{l}\text { "The Sixteen Personality Factor Questionnaire } \\
(16 \mathrm{PF}) \text { " (R. Cattell) }\end{array}$ & $\begin{array}{l}\text { A generalized characteristic of } \\
\text { human traits }\end{array}$ & $T_{6}$ \\
\hline 7 & $\begin{array}{l}\text { "Multi-level Personality Questionnaire } \\
\text { 'Adaptability"” (A. Maklakov, S. Chermyanin) }\end{array}$ & $\begin{array}{l}\text { Features of adaptation of a person } \\
\text { to new conditions, its tolerance to } \\
\text { changes }\end{array}$ & $T_{7}$ \\
\hline 8 & "Luscher Color Test" (modified by L. Sobchik) & Features of the emotional sphere & $T_{8}$ \\
\hline
\end{tabular}




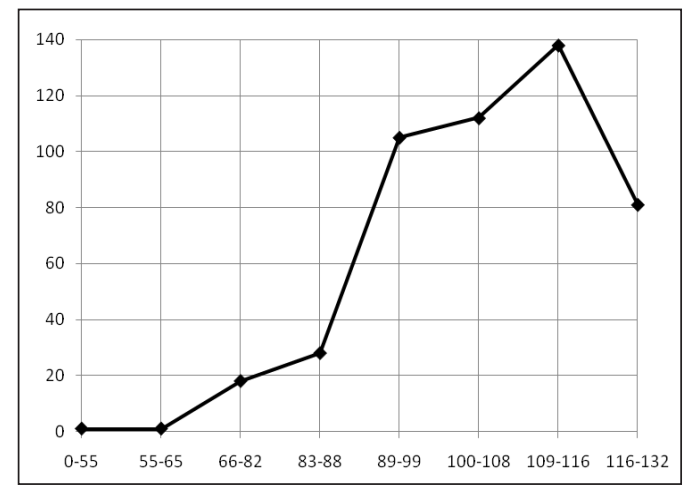

(a)

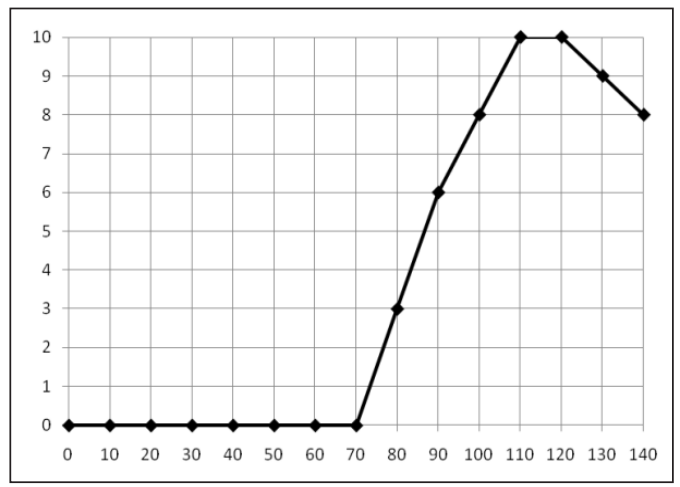

(b)

Figure 3. Distribution of intelligence points in the sample: (a) distribution function (maximum ordinate value is 138 points), (b) normalized distribution function (maximum ordinate value - 10, step after abscissa 10).

in Figure 3(a), and the normalized distribution function $F_{10}(a)$, taking into account the approximation, is shown in Figure 3(b).

A feature of the approximation of this indicator is the fact that an intelligence score of up to 70 "conditional points," inclusive, is not evaluated on a ten-point scale and is assigned a zero value. In addition, this indicator is professionally important, and the minimum necessary value is set for it in 6 normalized units of a ten-point scale. Let us present data comparing intelligence indicators in highly successful and poorly successful groups of military personnel (Table 2).

The data obtained indicate that highly successful military personnel have significantly higher indicators on the intelligence scale $(106.57 \pm 12.03)$ than poorly successful (98.82 \pm 12.72$)$, indicators of statistical significance of differences according to the Student's T-test and Fisher test $(\mathrm{t}=4.42, \mathrm{p} \leq 0.01)$. Thus, there is a significant relationship between the index of intelligence and the success of activities, but this relationship is weak. Table 3 shows the discrete normalized distribution function $F_{10}(a)$ after approximation. A similar approach is applied to the remaining scales of the selected tests.

Table 2

Intelligence indicators of military personnel of units with law enforcement functions (in conditional points)

\begin{tabular}{ccccc}
\hline Scales & Highly successful military personnel & Weak military personnel & $\mathrm{t}$ & $\mathrm{p}$ \\
\hline Intelligence & $106,57 \pm 12,03$ & $98,82 \pm 12,72$ & 4,42 & 0,01 \\
\hline
\end{tabular}

Table 3

Discrete values of the normalized distribution function after approximation

\begin{tabular}{ccccccccccccccccc}
\hline Points & 0 & 10 & 20 & 30 & 40 & 50 & 60 & 70 & 80 & 90 & 100 & 110 & 120 & 130 & 140 & Critical value \\
\hline$F_{10_{11}}(a)$ & 0 & 0 & 0 & 0 & 0 & 0 & 0 & 0 & 3 & 6 & 8 & 10 & 10 & 9 & 8 & 6 \\
\hline
\end{tabular}


Further, with the help of the APDC, the candidates of Group 2 were tested, the results were saved, the integral indicator of PS to service in units with law enforcement functions was calculated, and the candidate's suitability group was determined (I - suitable, II conditionally suitable, III - not suitable). The results obtained for Group 2 for a small sample $(\mathrm{n}=8)$ are shown (for example) in Table 4 . In Table 4 , columns $2-8$ show the results of tests calculated relative to a given psychological profile, in column 9 the integral indicator, and in column 10 the candidate's PS group.

The proposed method for determining a candidate's PS for a particular profession was developed to simplify the decision-making process based on the results of the PS of applicants. Implementing this method with the help of automated support systems contributes to the fastest and most reliable determination PS of a candidate. In addition, the developed method for determining the PS of a candidate involves the use of no more than three candidate suitability groups.

In contrast to the results of the studies Arestova et al. (1995), Grechushkina (2020), Zhiltsova et al. (2005), Zlepko et al. (2010), the developed method for calculating the integral indicator of the candidate's PS for a certain category of professions and the algorithm for forming a psychological profile for a particular profession allows obtaining a more reliable result in determining a person's ability to a certain category of professions. As a result of the conducted studies of Group 2, the time for testing, processing the results obtained, and making a decision on suitability was reduced by $73 \%$, the reliability of the results obtained (the presence of errors in the non-automated calculation of test scale values) improved by $7 \%$ compared to the results of Group 3. The effectiveness of the developed method is comparable with similar indicators used in the studies of Anitei and Buzea (2012), Kabak et al. (2012), Kelemenis and Askounis (2010).

The developed method also allows to research a large number of candidates, reduce the time for testing and processing the results, and avoid subjectivity when making a decision (Prykhodko, 2020). However, the reliability of a decision on PS largely depends

Table 4

Results of determining the PS candidates

\begin{tabular}{cccccccccc}
\hline Full name & $T_{1}$ & $T_{2}$ & $T_{3}$ & $T_{4}$ & $T_{5}$ & $T_{6}$ & $T_{7}$ & $P S^{*}$ & Group \\
\hline 1 & 2 & 3 & 4 & 5 & 6 & 7 & 8 & 9 & 10 \\
\hline Candidate 1 & 10 & 7.899 & 9 & 4.999 & 7.746 & 7.374 & 5.000 & 52.02 & II \\
Candidate 2 & 10.00 & 5.200 & 8 & 8 & 9.522 & 7.374 & 7.199 & 55.29 & I \\
Candidate 3 & 8.799 & 8.799 & 7.125 & 7.900 & 8.333 & 7.079 & 9.599 & 57.63 & I \\
Candidate 4 & 9.200 & 4.900 & 5.25 & 4.900 & 3.251 & 4.720 & 1 & 33.22 & III \\
Candidate 5 & 6.200 & 6.799 & 6.75 & 8.300 & 8.634 & 6.725 & 9.999 & 53.41 & II \\
Candidate 6 & 10 & 6.300 & 8.249 & 8.200 & 8.895 & 5.781 & 7.399 & 54.82 & I \\
Candidate 7 & 7 & 9.299 & 4.75 & 8.200 & 8.999 & 7.138 & 7.799 & 53.18 & II \\
Candidate 8 & 6.800 & 6.299 & 7 & 7.900 & 7.635 & 7.138 & 5.200 & 47.97 & II \\
\hline
\end{tabular}


on the accuracy and correctness of research on the formation of the characteristics of the psychological profile based on selected reference groups of specialists of a particular specialization (Prykhodko et al., 2020). Also important is the process of selecting the numerical values of the boundaries of groups of candidates, which depend on the number of selected tests and the given requirements for these groups (Cano, 2018).

All the obtained calculation data of the integral indicator of PS can be presented in text and graphic forms. Generalized data are synthesized for an individual respondent and a group united by a common attribute. Information can be made out in the form of tables according to the results of methods, scales, digital data, and graphs. In addition, a descriptive interpretation is made for each test indicator.

The developed method for determining PSP and APDC was implemented in the practical activities of the psychological service of the National Guard of Ukraine (NGU). In 2014-2016, the basics of the practical use of APDC at NGU were determined, and psychologists were trained to work with it. After the official consolidation of the developed method and the APDC in the regulatory documents in 2016, regulating the activities of the NGU psychological service, its practical use was carried out. To date, with his help, more than 20000 candidates for military service and NGU military personnel have undergone psychodiagnostic studies. In addition, constant monitoring studies are being carried out, which track the links between the effectiveness of the professional activities of military personnel with personality indicators measured and assessed by the APDC. In these studies, with a large sample of subjects, the reliability of the developed method was confirmed.

Further improvement of the method should improve forming a psychological profile with specified characteristics depending on the category of professions, justification, and correction of the values of the boundaries of the focus groups, and their automation.

\section{CONCLUSIONS}

As a result of the study, for the first time, the method was developed for calculating the integral indicator of the candidate's PS and an algorithm for forming a psychological profile for a specific profession. The developed method differs from the known ones in that the total PS indicator is calculated taking into account the totality of psychological characteristics of personality (cognitive, typological, characterological, neurodynamic, emotional-volitional, motivational). This method adapts the requirements of the profession to candidates, taking into account changes in the conditions of activity by adjusting the typical psychological profile of personality.

The algorithm for forming a psychological profile consists of the following stages: defining a set of tests; definition of reference groups of specialists and their testing; formation of a typical psychological profile of personality. The developed algorithm forming a psychological profile of personality with given characteristics, depending on 
the specialization, makes it possible to include an arbitrary number of psychodiagnostic tests. The number of tests and scales is determined when analyzing the requirements for professional activity and compiling a list of psychological characteristics that contribute to the successful mastery of this specialty and effective performance of official duties in real-life conditions.

The developed method for calculating the integral indicator of the candidate's PS is based on obtaining testing data on the selected scales of psychodiagnostic tests; their recalculation in accordance with the created typical psychodiagnostic profile and the summation of the data obtained. Thus, the general integral indicator includes all the characteristics of the candidate's personality, considering their importance.

The practical result of the research is the developed software toolkit for the method of determining the candidate's PS for a given category of professions in the form of an APDC "Psychodiagnostics." It reduces the time and labor costs for conducting psychodiagnostic studies, increases the reliability of tests due to a higher degree of standardization of the testing procedure, increases the accuracy of assessing psychological characteristics, and reduces the likelihood of errors in the processing of test results. In addition, the APDC accelerates the decision-making process based on test results due to the ability to calculate test scores and generate reports on the results quickly.

\section{ACKNOWLEDGEMENT}

The work presented in this paper has been supported by the Main Directorate of the National Guard of Ukraine (research project No. DR 0119U001475).

\section{REFERENCES}

Anitei, M., \& Buzea, E. (2012). Models and applications in psychological selection and evaluation. Procedia Social and Behavioral Sciences, 33, 756-760. https://doi.org/10.1016/j.sbspro.2012.01.223

Arestova, O. N., Babanin, L. N., \& Voyskunsky, A. E. (1995). Spetsifika psikhologicheskikh metodov v usloviyakh ispolzovaniya kompyutera [The specifics of psychological methods in terms of using a computer]. Publishing house of Moscow University.

Bodrov, V. A. (2007). Razvitiye sistemnogo podkhoda v issledovaniyakh professionalnoy deyatelnosti [The development of a systems approaches in the study of professional activities]. Psychological Journal, $28(3), 23-28$.

Campion, M. C., Campion, M. A., Campion, E. D., \& Reider, M. H. (2016). Initial investigation into computer scoring of candidate essays for personnel selection. Journal of Applied Psychology, 101(7), 958-975. https://doi.org/10.1037/ap10000108

Cano, A. (2018). Use of psychological test in personnel selection processes in consultants of human assumption resources. Eureka-Revista Cientifica De Psicologia, 15(1), 108-120. 
Farina, E. K., Thompson, L. A., Knapik, J. J., Pasiakos, S. M., McClung, J. P., \& Lieberman, H. R. (2019). Physical performance, demographic, psychological, and physiological predictors of success in the U.S. Army Special Forces Assessment and Selection course. Physiology \& Behavior, 210, Article 112647. https://doi.org/10.1016/j.physbeh.2019.112647

Grechushkina, E. (2020). Ispolzovaniye informatsionnykh tekhnologiy v psikhologo-pedagogicheskom soprovozhdenii podgotovki ofitserskikh kadrov [The use of information technology in the psychological and pedagogical support of the training of officer personnel]. Multipsikhometr.

Kabak, M., Burmaoğlu, S., \& Kazançoğlu, Y. (2012). A fuzzy hybrid MCDM approach for professional selection. Expert Systems with Applications, 39(3), 3516-3525. https://doi.org/10.1016/j.eswa.2011.09.042

Karpilovska, S. Y., Mitelman, R. Y., \& Synovsky, V. V. (1997). Osnovy profesiohrafiyi [Fundamentals of professiography]. MAUP.

Kelemenis, A., \& Askounis, D. (2010). A new TOPSIS-based multi-criteria approach to personnel selection. Expert Systems with Applications, 37(7), 4999-5008. https://doi.org/10.1016/j.eswa.2009.12.013

Langer, M., König, C. J., \& Busch, V. (2020). Changing the means of managerial work: Effects of automated decision support systems on personnel selection tasks. Journal of Business and Psychology, 36, 751-769. https://doi.org/10.1007/s10869-020-09711-6

Matsehora, Y. V., Prykhodko, I. I., Vorobyova, I. V., Horielyshev, S. A., \& Kazyanina, N. A. (2014). Psykholohichnyy monitorynh profesiyno vazhlyvykh yakostey kursantiv vyshchykh viyskovykh navchalnykh zakladiv MVS Ukrayiny [Psychological monitoring of professionally important qualities of cadets of higher military educational institutions of the Ministry of Internal Affairs of Ukraine]. IT MIA of Ukraine.

Melnyk, Y. B., Prykhodko, I. I., \& Stadnik, A. V. (2019). Medical-psychological support of specialists' professional activity in extreme conditions. Minerva Psichiatrica, 60(4), 158-168. https://doi.org/10.23736/ S0391-1772.19.02025-9

Ötting, S. K., \& Maier, G. W. (2018). The importance of procedural justice in human-machine interactions: Intelligent systems as new decision agents in organizations. Computers in Human Behavior, 89, 27-39. https://doi.org/10.1016/j.chb.2018.07.022

Parasuraman, R., Sheridan, T. B., \& Wickens, C. D. (2000). A model for types and levels of human interaction with automation. IEEE Transactions on Systems, Man, and Cybernetics - Part A: Systems and Humans, 30(3), 286-297. https://doi.org/10.1109/3468.844354

Petrescu, M., Burtăverde, V., Mihăilă, T., \& Mihaela, A. (2015). Situational judgments tests - A fact in call center personnel selection - Pilot study. Procedia - Social and Behavioral Sciences, 187, 762-766. https:// doi.org/10.1016/j.sbspro.2015.03.161

Prykhodko, I. I., Bielai, S. V., Hrynzovskyi, A. M., Zhelaho, A. M., Hodlevskyi, S. O., \& Kalashchenko, S. I. (2020). Medical and psychological aspects of safety and adaptation of military personnel to extreme conditions. Wiadomości Lekarskie, LXXIII(4), 679-683. https://doi.org/10.36740/WLek202004110

Prykhodko, I. I. (2008). Profesiynyy psykholohichnyy vidbir maybutnikh ofitseriv vnutrishnikh viysk MVS Ukrayiny [Professional psychological selection of future officers of the internal troops of the Ministry of Internal Affairs of Ukraine]. IT MIA of Ukraine. 
Ihor Prykhodko, Stanislav Horielyshev, Yanina Matsehora, Vasiliy Lefterov, Stanislav Larionov, Olena Kravchenko, Maksim Baida, Olena Halkina and Olena Servachak

Prykhodko, I. I. (Ed.). (2020). Avtomatyzatsiya profesiynoho psykholohichnoho vidboru kandydativ na viyskovu sluzhbu v Natsionalnu hvardiyu Ukrayiny [Automation of professional psychological selection of candidates for military service in the National Guard of Ukraine]. National Guard of Ukraine.

Sheridan, T. B., \& Parasuraman, R. (2005). Human-automation interaction. Reviews of Human Factors and Ergonomics, 1(1), 89-129. https://doi.org/10.1518/155723405783703082

Skorupski, J., Grabarek, I., Kwasiborska, A., \& Czyżo, S. (2020). Assessing the suitability of airport ground handling agents. Journal of Air Transport Management, 83, Article 101763. https://doi.org/10.1016/j. jairtraman.2020.101763

Spielberger, C. D. (Ed.). (2004). Encyclopedia of Applied Psychology. Academic Press.

Ventzel, E. S. (2006). Teoriya veroyatnosti [Probability theory]. Higher school.

Vorobyova, I. V., Prykhodko, I. I., Poltorak, S. T., Rutin, V. V., Timchenko, O. V., Lipatov, I. I., Matsehora, Y. V., Horielyshev, S. A., \& Poberezniy, A. A. (2012). Avtomatyzovanyy psykhodiahnostychnyy kompleks vyznachennya profesiynoyi prydatnosti kandydativ na viyskovu sluzhbu u vnutrishni viyska MVS Ukrayiny $i$ navchannya u vyshchykh viyskovykh navchalnykh zakladakh MVS Ukrayiny [Automated psychodiagnostic complex for determining the professional suitability of candidates for military service in the internal troops of the MIA of Ukraine and education in higher military educational institutions of the MIA of Ukraine]. IT MIA of Ukraine.

Zhiltsova, V. A., Zarakovsky, G. M., \& Ostrovsky, N. P. (2005). Osnovy voyennogo professionalnogo psikhologicheskogo otbora [Fundamentals of military professional psychological selection] (V. I. Lazutkin, Ed.). Military Publishing House.

Zlepko, S. M., Koval, L. H., Petrenko, V. V., \& Belzetskiy, P. S. (2010). Metody i zasoby psykhofiziolohichnoho vidboru kandydativ na sluzhbu za kontraktom v Zbroyni Syly Ukrayiny [Methods and means of psychophysiological selection of candidates for contract service in the Armed Forces of Ukraine]. Vinnytsia National Technical University Publishing House. 